\title{
BMJ Open Consideration of antimicrobial resistance and contextual factors in infectious disease guidelines: a systematic survey
}

\author{
Rosa Stalteri Mastrangelo, ${ }^{1,2}$ Nancy Santesso, ${ }^{1,3}$ Antonio Bognanni, ${ }^{1}$ \\ Andrea Darzi (D) ,1,3 Samer Karam, ${ }^{1,3}$ Thomas Piggott, ${ }^{1,3}$ Tejan Baldeh, ${ }^{3}$ \\ Finn Schünemann, ${ }^{3,4}$ Matthew Ventresca, ${ }^{1}$ Gian Paolo Morgano, ${ }^{1}$ Lorenzo Moja, ${ }^{5}$ \\ Mark Loeb, ${ }^{1}$ Holger Schunemann (i) ${ }^{1,3,4}$
}

To cite: Stalteri Mastrangelo $\mathrm{R}$, Santesso N, Bognanni A, et al. Consideration of antimicrobial resistance and contextual factors in infectious disease guidelines: a systematic survey. BMJ Open 2021;11:e046097. doi:10.1136/ bmjopen-2020-046097

- Prepublication history and supplemental material for this paper is available online. To view these files, please visit the journal online (http://dx.doi. org/10.1136/bmjopen-2020 046097).

Received 21 October 2020 Accepted 14 June 2021

A Check for updates

(c) Author(s) (or their employer(s)) 2021. Re-use permitted under CC BY-NC. No commercial re-use. See rights and permissions. Published by BMJ.

For numbered affiliations see end of article.

\section{Correspondence to} Dr Holger Schunemann; holger.schunemann@mcmaster. ca

\section{ABSTRACT}

Objectives Guidelines that include antimicrobial recommendations should explicitly consider contextual factors that influence antimicrobial resistance and their downstream effects on resistance selection. The objectives were to analyse (1) how, and to what extent, tuberculosis, gonorrhoea and respiratory tract infection guidelines are considering antimicrobial resistance; (2) are of acceptable quality and (3) if they can be easily contextualised to fit the needs of specific populations and health systems. Methods We conducted a systematic review and searched Ovid MEDLINE and Embase from 1 January 2007 to 7 June 2019 for tuberculosis, gonorrhoea and respiratory tract infection guidelines published in English. We also searched guideline databases, key websites and reference lists. We identified guidelines and recommendations that considered contextual factors including antimicrobial resistance, values, resource use, equity, acceptability and feasibility. We assessed quality of the guidelines using the Appraisal of Guidelines for Research and Evaluation II tool focusing on the domains scope and purpose, rigour of development, and editorial independence.

Results We screened 10365 records, of which 74 guidelines met inclusion criteria. Of these guidelines, 39\% $(n=29 / 74)$ met acceptable quality scores. Approximately two-thirds of recommendations considered antimicrobial resistance at the population and/or outcome level. Five of the 29 guidelines reported all factors required for recommendation contextualisation. Equity was the least considered across guidelines.

Discussion Relatively few guidelines for highly prevalent infectious diseases are considering resistance at a local level, and many do not consider contextual factors necessary for appropriate antimicrobial use. Improving the quality of guidelines targeting specific regional areas is required.

PROSPERO registration number CRD42020145235.

\section{INTRODUCTION}

Antimicrobials are essential to protecting human health. Their effectiveness is under threat due to antimicrobial resistance (AMR),
Strengths and limitations of this study

- This is the first study to assess whether guidelines are considering local dimensions such as antimicrobial resistance.

- We employed systematic methods and used established frameworks to assess the credibility of guidelines.

- By focusing on three key Appraisal of Guidelines for Research and Evaluation (AGREE) II domains and a relatively low score we were is inclusive but we included only English language publications.

- The use of the credibility cut-off score of $60 \%$ or greater for three of the six AGREE II domains is based on limited guidance on cut-off thresholds.

- We used criteria of the Grading of Recommendations, Assessment, Development and Evaluation Evidence to Decision Frameworks that are fairly general as they apply to any interventions and may need to be complemented with specific criteria related to the antimicrobial field.

resulting from misuse of antimicrobials over several decades. At the 2015 United Nations General Assembly, member states committed to address AMR by adopting national plans centred on five strategic objectives outlined in the WHO's Global Action Plan. ${ }^{2}$ The fourth objective of this plan is to implement national and hospital treatment guidelines for the optimisation of antimicrobial medicines use. ${ }^{2}$ Guidelines are among AMR stewardship interventions intended to modify clinician behaviour by providing guidance on when, and how, to prescribe antimicrobials, integrating information on antimicrobial consumption, resistance surveillance, research and development and burden of resistance. $^{3-5}$

Preservation of antimicrobials requires the consideration of how, and under what 
conditions, is it appropriate to recommend antimicrobials. However, only a small number of recently published guidelines considered epidemiological and resistance pattern data. ${ }^{6}$ There are also concerns that guidelines are not considering important contextual factors, including evidence on values, resource use, equity, acceptability and feasibility that go beyond resistance patterns and that may influence secular trends in AMR. ${ }^{78}$ For example, guideline recommendations are likely to better support effective use of antimicrobials in specific contexts when they account for how much people value the affected health outcomes ('values'), AMR burden, public health infrastructure, local medicine policies for consistent access to safe, effective, affordable medicines and equitability of antimicrobial regimens. ${ }^{9}$ Considering these factors is also relevant for adapting and implementing. The failure to account for these factors likely results from the lack of formal guidance for developing recommendations that consider AMR and other local factors.

Incomplete reporting of evidence supporting recommendations, and the existing belief that guideline developers must develop their recommendations 'from scratch', results in additional challenges. Scientific societies and other organisations duplicate the same work to develop recommendations resulting in multiple guidelines on the same topic, confusion and loss of confidence by clinicians, and resource waste. ${ }^{810}$ However, guideline processes can become more effective, if they can be effectively adapted by others. This process requires transparent reporting of how the guideline development groups moved from evidence to recommendations, and properly include AMR. Formal processes for adaptation permit societies and organisations to capitalise on existing evidence evaluation and interpretation by considering important contextual factors, among which AMR is the most noticeable. This would reduce cost and redundancy. ${ }^{7}$

Our objectives were to analyse how, and to what extent, tuberculosis $(\mathrm{TB})$, gonorrhoea and respiratory tract infection guidelines are considering AMR; are of acceptable methodological quality; and if they can be easily contextualised to fit the needs of specific populations.

\section{METHODS}

\section{Selection criteria and search strategy}

We selected three types of infection: TB, gonorrhoea and respiratory tract infections, specifically otitis media, pharyngitis, sinusitis and community-acquired pneumonia. These infections are a public health priority because they are becoming increasingly harder to treat due to AMR and/or are treated inappropriately, leading to higher risk of toxicity or resistance development. Harder to treat drug-resistant TB strains are increasing and projected to account for a quarter of all TB deaths by $2050 .{ }^{11}$ Neisseria gonorrhoea is an urgent public health threat. ${ }^{12}$ The international spread of resistance to the last effective therapy, ceftriaxone and azithromycin, threatens sustained treatment of gonorrhoea. ${ }^{13} 14$ Otitis media, pharyngitis, sinusitis and community-acquired pneumonia are prevalent and Streptococcus pneumoniae (the main causal microorganism), was classified as a serious public health threat due to resistance observed by inappropriate use of antibiotics. ${ }^{12}{ }^{15}$ All these syndromes have been prioritised by WHO as part of Access, Watch and Reserve (AWaRe)-a new classification system that supports a more nuanced approach to target inappropriate use of broad spectrum 'Watch' antibiotics. ${ }^{16}$

We included English language guidelines published between 2007 and 2019 on the above selected infections. We restricted to English language guidelines because, from a practical standpoint, English language publications would be the simplest to contextualise for most international groups and the major international organisations like WHO publish their guidelines at least in English. We marked the 2007 WHO decision to update its guideline development and using the Grading of Recommendations, Assessment, Development and Evaluation (GRADE) approach as a major change in methodology, representing a division of two eras. ${ }^{17}$ We limited the focus of our analyses to the era following this change.

We included guidelines with clearly articulated recommendations as defined by the Institute of Medicine Standards for Developing Trustworthy Clinical Practice Guidelines. ${ }^{14}$ After contacting guideline developers, we excluded guidelines with unobtainable online supplemental materials required for analysis (see online supplemental table 1S) for our guideline and recommendation selection outlined in PICAR format).

We searched Ovid MEDLINE and Embase from inception to 7 June 2019 (detailed search strategies in online supplemental material). We conducted a second search in four guideline databases: Turning Research Into Practice (https://www.tripdatabase.com), Guidelines International Network (https://www.g-i-n.net/home), BIGG (http://sites.bvsalud.org/bigg/en/biblio/) and the Canadian Medical Association clinical practice guideline (CPG) Infobase (https://joulecma.ca/cpg/homepage). We finally searched key international websites (online supplemental table $2 \mathrm{~S}$ ) and reviewed references of included guidelines.

Independently and in pairs, reviewers (RSM, AB, $\mathrm{AD}$, MV, GPM, SK and TB) screened titles and abstracts and the full text of potentially eligible guidelines. Disagreements were resolved by discussion or with a third reviewer (NS and HS).

\section{Data extraction and quality assessment}

We extracted data from guidelines, retrievable online supplemental materials and guideline development documents facilitated by pilot-tested forms and distillerSR (https://www.evidencepartners.com). Extractors (RSM, AB, AD, FS, GPM, MV and SK) recorded data independently and in pairs, and resolved disagreements.

Reviewers screened through recommendations classifying them as either considering AMR or not according to 
Table 1 Satisfactory recommendations that consider antimicrobial resistance (AMR) dimensions

\begin{tabular}{ll}
\hline AMR dimension(s) & Recommendation \\
\hline $\begin{array}{ll}\text { AMR population- } \\
\text { level dimensions }\end{array}$ & $\begin{array}{l}\text { Amoxicillin-clavulanate rather than amoxicillin } \\
\text { considered }\end{array}$ \\
& $\begin{array}{l}\text { therapy for Acute Bacterial Rhinosinusitis (ABRS) in } \\
\text { adults (weak, low). }{ }^{13}\end{array}$
\end{tabular}

AMR outcome-

level dimensions considered
In neonates with gonococcal conjunctivitis, the WHO sexually transmitted infections (STIs) guideline suggests one of the following treatment options:

- Ceftriaxone 50 mg/kg (maximum 150 mg) intramuscular (IM) as a single dose.

- Kanamycin 25 mg/kg (maximum 75 mg) IM as a single dose.

- Spectinomycin 25 mg/kg (maximum 75 mg) IM as a single dose..$^{89}$

$\begin{array}{ll}\text { Population and } & \text { Bedaquiline should be included in longer } \\ \text { outcome-level } & \text { multidrug-resistant (MDR) TB regimens for patients } \\ \text { dimensions } & \text { aged } 18 \text { years or more (strong recommendation, } \\ \text { considered } & \text { moderate certainty in the estimates of effect). }{ }^{90}\end{array}$

Alternative first choice of antibiotics for adults aged 18 years and over with pharyngitis and a penicillin allergy or intolerance: Clarithromycin $250 \mathrm{mg}$ to $500 \mathrm{mg}$ wo times per day a day for 5 days days. ${ }^{55}$

\section{Evidence illustration}

Local national surveillance data in the United States of America for amoxicillin and beta-

in lactamase-producing Haemophilus influenzae was narratively described in the evidence summary was clearly linked to the recommendation.

The outcome of 'AMR' was formally considered within a PICO framework within the guideline's online supplemental file 1.
The recommendation considers a multidrugresistant TB patients, and the outcome 'acquisition (amplification) of drug resistance, 91 was formally considered within a PICO framework provided within the guideline's supplemental materials.

Summary of committee discussions show that population-level resistance data was considered: 'based on evidence, clinical experience and resistance data, the committee agreed to recommend the following alternative firstchoice antibiotics for use in penicillin allergy or for phenoxymethylpenicillin intolerance: clarithromycin or erythromycin (which is preferred in pregnancy)' ${ }^{55}$ Additional formal outcome considerations include 'antibiotic resistance' within the guideline's supplemental materials.

PICO, population, intervention, comparison, and outcome; TB, tuberculosis.

AMR dimensions (examples provided in table 1 and online supplemental table 3S). Although guidelines may have adopted different approaches to considering resistance with varying level of technicalities and detail, our operational definitions for considering a guideline 'compliant' were inclusive. We assumed that for each recommendation, there would be an opportunity to consider information pertaining to AMR at the population and outcome level, given that formulation of specific recommendations is guided by population, intervention, comparison and outcome (PICO) frameworks. Population-level considerations include recommendations for populations with some level of resistance, considerations of local resistance patterns, recommending the use of narrow-spectrum antimicrobials and recommending the watchful-waiting approach to prescribing. Outcome-level dimensions included considering prospects of AMR or the emergence of resistance as a consequence of antimicrobial use.

We considered a guideline satisfactory if it reports information on any of the above dimensions in either the recommendation, accompanying evidence summaries or PICO framework. Whereas guidelines that generally discussed AMR as an issue, without linking information pertaining to AMR to each recommendation were considered unsatisfactory.

We assessed a guideline's quality using the Appraisal of Guidelines for Research and Evaluation (AGREE) II Instrument focusing on three relevant domains: a welldefined scope and purpose (domain one), rigorous development including a systematic search for evidence, transparent reporting of methods, links between evidence and recommendations, external review and procedures for update (domain three), and editorial independence (domain six). ${ }^{18}$ We defined acceptable quality as guidelines that scored $60 \%$ or greater in these three domains a priori based on limited guidance on cut-off thresholds. ${ }^{3} 19$ Focusing on these three domains and selecting a relatively low score, allowed us to be inclusive.

We also abstracted information on values, resource use, equity, acceptability and feasibility from guidelines that met our acceptability cut-off (ie, 60\%). Briefly, worldwide regions may differ in the accessibility of antimicrobials, the cultural view towards the use of antimicrobials, pharmaceutical costs and healthcare structures. We selected these dimensions as the transparent reporting of these factors is essential: in appraising the evidence for antimicrobials, 
guideline developers should be aware of the breadth of implications of their recommendations when used by decision-makers. ${ }^{7102021}$ Guidelines that ignore this wider agenda could provide narrow, misleading guidance.

\section{Data synthesis and statistical analysis}

We conducted descriptive statistics at the guideline and recommendation level, using counts and proportions (95\% CI). We calculated the mean (SD) for AGREE II scores by region. We also compared the quality of guidelines from the WHO versus regional guidelines using scaled domain scores, mean difference, and a two-sided t-test. We calculated the frequency of guideline reporting of values, resource use, equity, acceptability and feasibility. All analyses were conducted in Microsoft Excel and R-Studio (RStudio Team (2016). RStudio: Integrated Development for R. RStudio, Boston, Massachusetts, USA, URL http://wwwrstudiocom/.).

This paper is reported according to the Preferred Reporting Items for Systematic Reviews and Metaanalyses guidelines and internally funded by the Michael G. DeGroote Cochrane Canada and McMaster GRADE centres.

\section{Patient and public involvement}

One of the authors is a patient with a rare disease affected by repeated infections and treatment related issues of resistance to antimicrobials and was involved in aspects of the design and data abstraction. We specifically looked for information about patient values and preferences and included this in our review. However, we did not make any additional specific efforts to involve the patient and public in other aspects of this systematic review.

\section{RESULTS}

Our initial search identified 10365 records. After screening, we retrieved 79 guidelines that had at least one recommendation on antimicrobial selection: $(n=28 \mathrm{~TB}$, $\mathrm{n}=13$ gonorrhoea, $\mathrm{n}=38$ respiratory tract infections). Of these, 78 guidelines had sufficient information for assessment-one gonorrhoea guideline was excluded because we were unable to retrieve supplemental materials (figure 1 and online supplemental table $4 \mathrm{~S}$ ). ${ }^{22}$

\section{Guideline recommendations considering AMR}

After classifying recommendations, we found that 74 guidelines had at least one recommendation that considered AMR and four guidelines without such considerations (table 2). ${ }^{23-26}$ These were excluded from further assessment. Of the 74 guidelines, the majority were developed in North America $(n=29),{ }^{13} 22$ 27-54 and Europe $(\mathrm{n}=26){ }^{4455-78}$ A smaller portion were from Asia $(\mathrm{n}=7),{ }^{79-85}$ South America $(n=1),{ }^{86}$ Africa $(n=1)^{87}$ and Oceania $(n=1) .{ }^{88}$ Nine guidelines were internationally developed by the WHO. ${ }^{89-97}$

Within these 74 guidelines, we found that approximately two-thirds of recommendations $(n=808 / 1198)$ considered

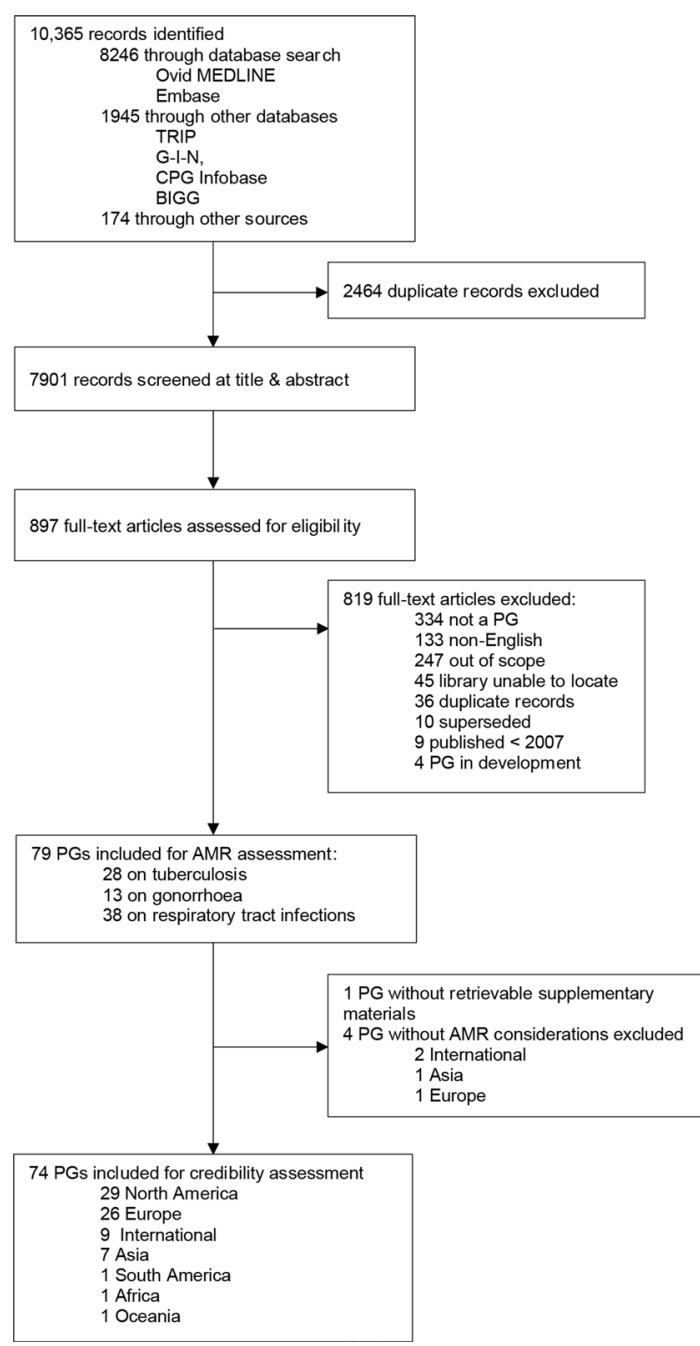

Figure 1 Flow diagram of the guideline selection process. BIGG, International database of GRADE guidelines; CPG infobase, Canadian Medical association CPG Infobase; out of scope, does not include recommendations on antibiotic selection or prescribing; does not have a significant section on tuberculosis, gonorrhoea, or respiratory tract infections. AMR, antimicrobial resistance; CPG, clinical practice guideline; G-I-N, Guidelines International Network; GRADE, Grading of Recommendations, Assessment, Development and Evaluation; PG, practice guideline; TRIP, Turning Research Into Practice.

AMR; that figure was $55.2 \%$ for $\mathrm{TB}$ recommendations $(\mathrm{n}=272), 84.7 \%$ for gonorrhoea recommendations $(\mathrm{n}=150)$ and $73.1 \%$ for respiratory tract infection recommendations $(\mathrm{n}=386)$. The majority of recommendations were regionally developed $(\mathrm{n}=736)$ (figure 2$)$.

Most recommendations considered either populationlevel or outcome-level AMR dimensions, while fewer considered both simultaneously. Approximately $17.6 \%$ of recommendations $(n=142 / 808)$ considered AMR at the population-level only while $34.7 \% \quad(n=281 / 808)$ of recommendations considered resistance as an outcome only. Most notably, a majority of those considering AMR as an outcome were not explicitly stated in PICO format, but rather buried within evidence summaries. Clearly 
Table 2 Guidelines and recommendations with treatment recommendations with $\mathrm{AMR}^{*}$ considerations

\begin{tabular}{|c|c|c|c|c|}
\hline Variable & $\begin{array}{l}\text { Guidelines } \\
(\mathrm{N}=78+)\end{array}$ & $\begin{array}{l}\text { Total no of } \\
\text { recommendations } \\
\text { ( } \mathrm{N}=1198)\end{array}$ & $\begin{array}{l}\text { No of recommendations } \\
\text { with AMR consideration } \\
\text { ( } \mathrm{N}=808)\end{array}$ & $\begin{array}{l}\text { Proportion of } \\
\text { recommendations with AMR } \\
\text { consideration }(95 \% \mathrm{Cl})\end{array}$ \\
\hline \multicolumn{5}{|l|}{ Continent } \\
\hline Internationalł & 11 & 93 & 72 & 0.77 (0.67 to 0.85$)$ \\
\hline North America & 29 & 503 & 321 & 0.64 (0.59 to 0.68$)$ \\
\hline South America & 1 & 26 & 7 & 0.27 (0.12 to 0.48$)$ \\
\hline Europe & 27 & 429 & 334 & 0.78 (0.74 to 0.82$)$ \\
\hline Africa & 1 & 24 & 8 & $0.33(0.16$ to 0.55$)$ \\
\hline Asia & 8 & 119 & 65 & 0.55 (0.45 to 0.64$)$ \\
\hline Oceania & 1 & 4 & 1 & 0.25 (0.01 to 0.78 ) \\
\hline \multicolumn{5}{|l|}{ Publication year } \\
\hline 2007 & 3 & 47 & 34 & 0.72 (0.57 to 0.84 ) \\
\hline 2008 & 2 & 4 & 4 & $1.00(0.40$ to 1.00$)$ \\
\hline 2009 & 6 & 175 & 92 & 0.53 (0.45 to 0.60$)$ \\
\hline 2010 & 3 & 45 & 30 & 0.67 (0.51 to 0.80$)$ \\
\hline 2011 & 8 & 77 & 64 & $0.83(0.72$ to 0.90$)$ \\
\hline 2012 & 10 & 144 & 96 & 0.67 (0.58 to 0.74$)$ \\
\hline 2013 & 7 & 121 & 3 & 0.77 (0.68 to 0.84$)$ \\
\hline 2014 & 5 & 167 & 88 & 0.53 (0.45 to 0.60$)$ \\
\hline 2015 & 7 & 37 & 35 & 0.95 (0.80 to 0.99 ) \\
\hline 2016 & 10 & 83 & 3 & 0.64 (0.53 to 0.74$)$ \\
\hline 2017 & 6 & 129 & 94 & 0.73 (0.64 to 0.80$)$ \\
\hline 2018 & 5 & 49 & 45 & 0.92 (0.80 to 0.97$)$ \\
\hline 2019 & 6 & 120 & 80 & 0.67 (0.57 to 0.75$)$ \\
\hline
\end{tabular}

*AMR, antibiotic resistance.

$\dagger 4 / 78$ guidelines did not have recommendations that considered resistance.

†International, WHO.

AMR, antimicrobial resistance.

stated outcomes formally considered in PICO frameworks included: 'acquired drug-resistance', 'antimicrobial in vitro resistance', 'bacterial antibiotic resistance', and 'emergence of drug-resistance'. Among respiratory tract infection recommendations, $6.9 \% \quad(\mathrm{n}=27 / 386)$
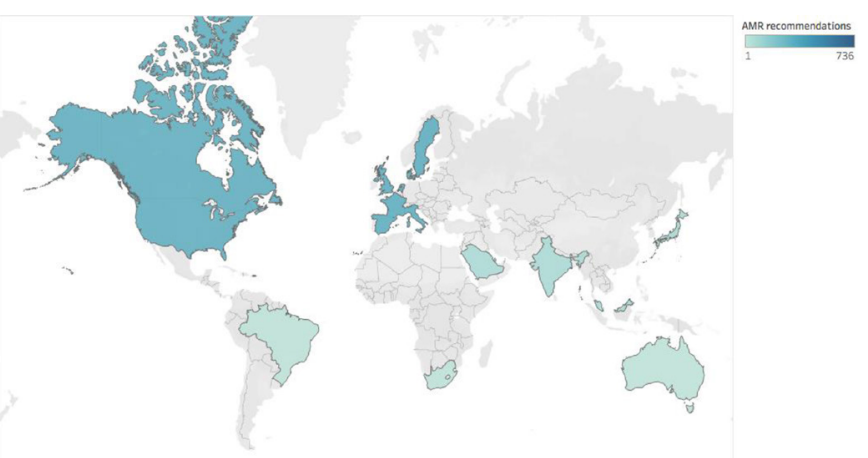

Figure 2 Number of regional guideline recommendations that consider antimicrobial resistance. AMR, antimicrobial resistance. recommended no antimicrobial or back-up antimicrobial (ie, the watchful waiting approach), which is a population-level dimension, for example, recommendations for patients who likely have infections that are viral in nature or self-limiting.

Additionally, $47.6 \%(385 / 808)$ recommendations considered both population-level and outcome-level AMR dimensions simultaneously. For example, fully immunised infant or school-aged children with community-acquired pneumonia admitted to hospital are recommended to take ampicillin or penicillin $\mathrm{G}$ given that local epidemiologic data lacks a substantial high level of penicillin resistance for invasive Streptococcus pneumoniae. ${ }^{33}$ This recommendation is considering local resistance patterns (population-level dimension). It is also followed by an evidence summary the explains that lower costs of ampicillin or penicillin $\mathrm{G}$ need to be balanced by the increased possibility of emergence of resistance (outcomelevel dimension) that may occur from prescribing broadspectrum antimicrobials. About 22.5\% (n=182/808) of recommendations considered local resistance patterns in a similar manner. 


\begin{tabular}{|c|c|c|c|c|}
\hline AGREE II scores & $\begin{array}{l}\text { WHO guidelines } \\
(n=9)\end{array}$ & $\begin{array}{l}\text { Regional } \\
\text { guidelines }(n=65)\end{array}$ & $\begin{array}{l}\text { Mean difference } \\
(95 \% \mathrm{Cl})\end{array}$ & $P$ value \\
\hline \multicolumn{5}{|l|}{ Domain 1: Scope and purpose } \\
\hline Mean domain score \% (SD) & $89^{13}$ & $71^{55}$ & $-18(-0.28$ to to 0.06$)$ & 0.004 \\
\hline Score range as $\%$ & $69-100$ & $17-100$ & & \\
\hline Scored $60 \%$ or greater as $\%(n)$ & $100(n=9)$ & $68(n=44)$ & & \\
\hline \multicolumn{5}{|l|}{ Domain 3: Rigour of development } \\
\hline Mean domain score \% (SD) & $81^{19}$ & $51^{18}$ & $-30(-0.50$ to to 0.11$)$ & 0.005 \\
\hline Score range as $\%$ & 20-99 & $6-98$ & & \\
\hline Scored $60 \%$ or greater as $\%(n)$ & $89(n=8)$ & $37(n=24)$ & & \\
\hline \multicolumn{5}{|l|}{ Domain 6: Editorial independence } \\
\hline Mean domain score \% (SD) & $88^{90}$ & $56^{25}$ & $-32(-0.48$ to to 0.15$)$ & 0.001 \\
\hline Score range as $\%$ & $38-100$ & $0-100$ & & \\
\hline Scored $60 \%$ or greater as $\%(n)$ & $89(n=8)$ & $49(n=32)$ & & \\
\hline
\end{tabular}

AGREE II, Appraisal for Guidelines Research and Evaluation II; AMR, antimicrobial resistance.

\section{Credibility of international and regional guidelines with} recommendations that consider AMR

Overall, only $39.2 \%(n=29 / 74)$ of all international and regional guidelines had scores of $60 \%$ or greater in scope and purpose, rigour of development, and editorial independence. Of the 29 guidelines that met our credibility cut-off, 10 were developed in North America, ${ }^{13} 34-39425398$ nine in Europe ${ }^{445564676872-7587}$ and two were developed in Asia. ${ }^{80}{ }^{82}$ When we compared international and regional guidelines, the majority of WHO guidelines performed significantly better than regional guidelines (table 3, online supplemental figure 1S). Guidelines that did not meet our credibility cut-off score and excluded from further assessment included: 19 from North America, 17 from Europe, 5 from Asia and 3 guidelines from South America, Africa and Oceania.

Guidelines considering values, resource use, acceptability, feasibility and equity

Only $5^{89} 90939496$ of the 29 guidelines reported all factors required for contextualisation: values, resource use, equity, acceptability and feasibility (online supplemental table 5S). The WHO was the only guideline developer to report on all five criteria in four $\mathrm{TB}$ guidelines and one gonorrhoea guideline.

Across all 29 guidelines, resource use was the most frequently considered ( $\mathrm{n}=23$ guidelines), followed by values ( $\mathrm{n}=16$ guidelines), acceptability ( $\mathrm{n}=12$ guidelines) and feasibility ( $\mathrm{n}=12$ guidelines). Equity was the least considered factor with only seven guidelines that made such considerations (figure 3): two were regionally and five were internationally developed. The WHO, the National Institute for Health and Care Excellence (NICE) and the US Preventative Task Force were the only organisations to consider equity.

Regional guidelines tended to consider values, resource use, equity, acceptability and feasibility less than internationally developed guidelines (online supplemental figure 2S). Most regional guidelines considered one $(n=6 / 21)$ or two $(n=6 / 21)$ or three $(n=4 / 21)$ or none $(n=4 / 21)$ of the above contextual factors. Values and resource use were considered the most, while equity, acceptability and feasibility were less considered in regionally developed guidelines (figure 4).

\section{DISCUSSION}

\section{Summary of findings}

Over a 13-year period, relatively few guidelines on antibiotics for highly prevalent infectious diseases included AMR considerations. Approximately $60 \%$ of regionally developed guidelines were of low quality and reported less factors required for tailoring recommendations to specific

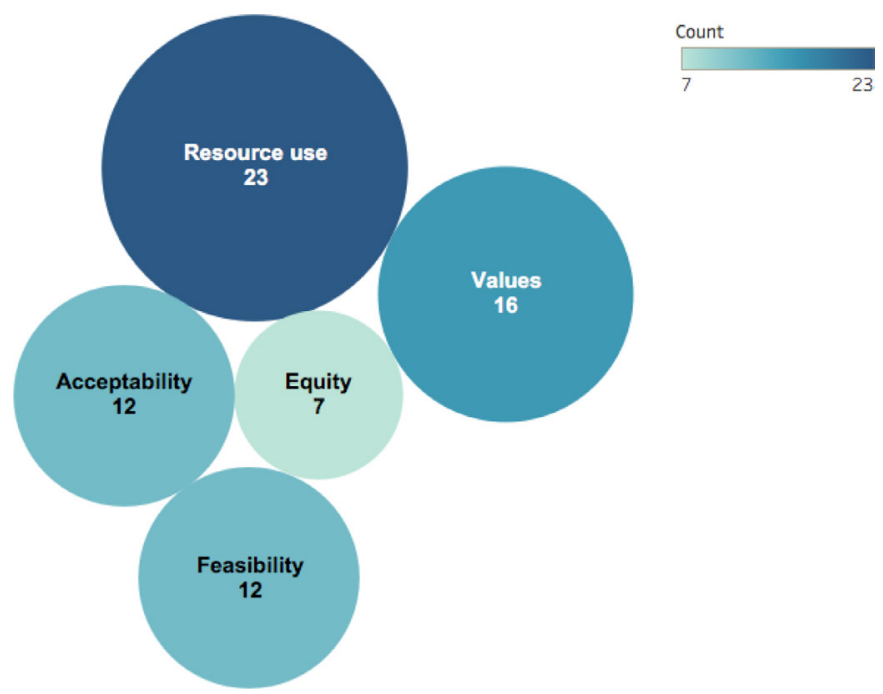

Figure 3 Contextualisation of Grading of Recommendations Assessment, Development and Evaluation evidence to decision frameworks in current guidelines. 


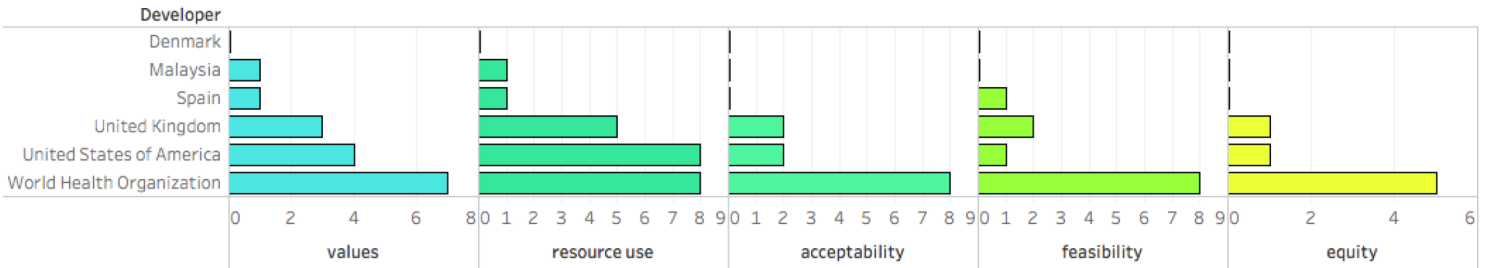

Figure 4 Number of internationally and regionally developed guidelines with considerations of Grading of Recommendations Assessment, Development and Evaluation evidence to decision frameworks.

contexts. International WHO guidelines had substantially higher quality scores than regional guidelines. International guidelines also consistently considered important information required for developing recommendations that are appropriate for specific contexts compared with regional guidelines.

There is an emerging consensus that reporting of Evidence to Decision dimensions is ethically and scientifically essential. Unfortunately, reporting these dimensions is not always seen in practice. Our review highlighted that some of the proposed dimensions seemed to be adopted by guideline developers (ie, values and resource use were most considered), while others were less so (ie, acceptability, feasibility and equity were the least considered). Further, the quality of these guidelines varied and there were inconsistencies between regions and guidelines promoted/sponsored by different entities.

The use of the GRADE Evidence to Decision framework by the WHO and NICE seems to positively influence the consideration of contextual factors in the guidelines we reviewed. A high proportion of WHO $(n=5 / 7)$ and NICE $(n=1 / 5)$ guidelines contained complete information necessary to provide optimal guidance on how to use antimicrobials in the considered syndromes. Other regional organisations provided limited information addressing contextual factors - most addressed one $(n=6 / 21)$ or two $(n=6 / 21)$ contextual factors and a good proportion did not address any $(4 / 21)$.

\section{Strengths and limitations}

Our work has strengths. To our knowledge, this is the first study to assess the extent to which guidelines are considering local dimensions such as AMR, and to use established frameworks: AGREE II and GRADE Evidence to Decision. We also employed systematic methods to conduct our review and validated tools to measure the quality of guidelines. ${ }^{3} 18$

There are several limitations to our study. The use of a credibility score of $60 \%$ or greater for three of the six AGREE II domains is based on limited guidance on cut-off thresholds. However, by focusing on three domains and a low cut-off we were inclusive although we also focused on English language publications only. ${ }^{399}$ We used general criteria from the GRADE Evidence to Decision Frameworks that are applicable to various interventions, and not specific to antimicrobials. These general dimensions could be complemented with specific criteria related to the antimicrobial field such as providing guidance on the appropriate threshold for escalating empiric antimicrobials from narrower spectrum agents to broad-spectrum agents. In other words, the real test for antimicrobial guidelines may be whether they enable prescribers and the public to fully consider the potential implications of antimicrobial prescribing on resistance. This would lead to virtuous and parsimonious prescribing and consumption habits.

\section{Context to other research}

We previously found that about two thirds of respiratory tract infection recommendations on empirical antimicrobial use did not consider country-specific resistance patterns. The use of a broader framework and additional focus areas may have resulted in the larger number of recommendations that considered AMR uncovered by this study. Both studies support that there are inconsistencies in considering AMR in recommendation development and potential duplication of work among infectious disease guidelines.

\section{Implications for practice}

There are several implications for guideline developers. Given the suboptimal quality of guidelines in our sample, guideline methodology should improve particularly when recommendations move from global to regional levels. This includes improving the processes used in evidence syntheses and recommendation formulation, transparency and addressing potential unduly biases with competing interests. As far as regional guidelines need to incorporate contextual information when developing their recommendations, global guidelines need to provide information about how to contextualise recommendations for appropriate AMR considerations.

Guideline development can be done more efficiently and economically by using work done by other developers including the WHO. Rather developing guidelines from scratch, time and resources ${ }^{100}$ may be shifted towards refining AMR surveillance systems that provide national resistance data to support recommendations and appropriate antimicrobial use. Further, country-level participation of the Global Antimicrobial Resistance Surveillance System (GLASS) supports global monitoring of resistance trends, emerging resistance and the ability to evaluate the effectiveness of interventions. ${ }^{101}$ As of 2020, 94 countries are participating in GLASS. ${ }^{101}$ However, some countries lack public health infrastructure, national laboratory capacities, and data management which is essential for 
surveillance systems. ${ }^{6} 102$ In 2018, there was at least one country within each WHO regions with the ability to collect national resistance data. ${ }^{102}$ Regions facing unique challenges to antimicrobial stewardship capacities, may look to recommendations developed by other regions with similar resistance experiences. Finally, as new antimicrobial therapies become available, and the scientific community cumulates more evidence on resistance patterns and their implications for local prescribing, future infectious disease guidelines may require more frequent updating.

\section{Implications for research}

Although we focused on recommendations on antimicrobial selection and prescribing, there are many other approaches that could be assessed in future research $(\mathrm{eg}$, rapid diagnostics to rule-out viral infections and resistant strains). In addition, research should also explore whether recommendations are appropriately guided by evidence, resistance data and the WHO's Essential Medicines List and AWaRe Classification Database of Antimicrobials updates. ${ }^{103}$ With regard to contextualisation of infectious disease recommendations, we have developed transparent recommendation maps that facilitate use of recommendations across jurisdictions for TB (https:// who.tuberculosis.recmap.org) and COVID-19 (https:// COVID-19.recmap.org) where we apply some of our findings.

\section{CONCLUSION}

Our study offers information on how current infectious disease guidelines are considering contextual factors necessary to appropriately prescribe antimicrobials. We also present dimensions that can be considered by a formal AMR framework used in combination with GRADE Evidence to Decision Frameworks to facilitate amelioration of the cornerstones that are guiding current antimicrobial use. Improving the quality of guidelines targeting specific regional areas is required. This may help to protect the remaining and essential medicines we have left, and the future of new classes of antimicrobials. ${ }^{104}$

\section{Author affiliations}

${ }^{1}$ Department of Health Research Methods, Evidence and Impact, McMaster University, Hamilton, Ontario, Canada

${ }^{2}$ Institute of Health Policy, Management and Evaluation, University of Toronto, Toronto, Ontario, Canada

${ }^{3}$ Michael G. DeGroote Cochrane Canada and MacGRADE Centres, McMaster University, Hamilton, Ontario, Canada

${ }^{4}$ Institut für Evidence in Medicine, Medical Center \& Faculty of Medicine, University of Freiburg, Freiburg, Germany

${ }^{5}$ Department of Health Product Policy and Standards, World Health Organization, Geneva, Switzerland

Acknowledgements This work was supported by the Michael G. DeGroote Canada and McMaster GRADE centres. We would like to thank biostatistician Dr. Thuva Vanniyasingam for assisting with developing an analysis plan for our protocol.

Contributors RSM, HS, NS, ML and TP designed the study protocol. RSM coordinated the study. RSM, AB, AD, GPM, MV, SK and TB assessed eligibility of records at title and abstract. $R S M, A D$ and $M V$ searched for unpublished guidelines in key websites. RSM, AB, AD, GPM, MV, and SK assessed eligibility of full text articles. RSM, AB, AD, FS, GPM, MV and SK extracted data and performed quality assessment using the AGREE II tool. NS and HS settled disputes. RSM analysed and interpreted the data with HS, NS and ML. RSM and HS drafted the manuscript, with writing contributions from NS, ML and LM. All authors interpreted and make edits to the manuscript.

Funding Michael G. DeGroote Cochrane Canada and McMaster GRADE centres.

Map disclaimer The depiction of boundaries on the map(s) in this article does not imply the expression of any opinion whatsoever on the part of BMJ (or any member of its group) concerning the legal status of any country, territory, jurisdiction or area or of its authorities. The map(s) are provided without any warranty of any kind, either express or implied.

Competing interests None declared.

Patient consent for publication Not required.

Provenance and peer review Not commissioned; externally peer reviewed.

Data availability statement All data relevant to the study are included in the article or uploaded as online supplemental information. No additional data available.

Supplemental material This content has been supplied by the author(s). It has not been vetted by BMJ Publishing Group Limited (BMJ) and may not have been peer-reviewed. Any opinions or recommendations discussed are solely those of the author(s) and are not endorsed by BMJ. BMJ disclaims all liability and responsibility arising from any reliance placed on the content. Where the content includes any translated material, BMJ does not warrant the accuracy and reliability of the translations (including but not limited to local regulations, clinical guidelines, terminology, drug names and drug dosages), and is not responsible for any error and/or omissions arising from translation and adaptation or otherwise.

Open access This is an open access article distributed in accordance with the Creative Commons Attribution Non Commercial (CC BY-NC 4.0) license, which permits others to distribute, remix, adapt, build upon this work non-commercially, and license their derivative works on different terms, provided the original work is properly cited, appropriate credit is given, any changes made indicated, and the use is non-commercial. See: http://creativecommons.org/licenses/by-nc/4.0/.

\section{ORCID iDs}

Andrea Darzi http://orcid.org/0000-0002-2498-1697

Holger Schunemann http://orcid.org/0000-0003-3211-8479

\section{REFERENCES}

1 United Nations meeting on antimicrobial resistance. United nations meeting on antimicrobial resistance. Bull World Health Organ 2016;94:638-9.

2 Organization WH. Global action plan on antimicrobial resistance, 2015. ISBN: 9789241509763.

3 Johnston A, Kelly SE, Hsieh S-C, et al. Systematic reviews of clinical practice guidelines: a methodological guide. J Clin Epidemiol 2019;108:64-76.

4 Canada PHAo. Tackling antimicrobial resistance and antimicrobial use: a Pan-Canadian framework for action. Canada, 2017. ISBN 978-0-660-08168-7.

5 Anderson M, Schulze K, Cassini A, et al. A governance framework for development and assessment of national action plans on antimicrobial resistance. Lancet Infect Dis 2019;19:e371-84.

6 Elias C, Moja L, Mertz D, et al. Guideline recommendations and antimicrobial resistance: the need for a change. BMJ Open 2017:7:e016264.

7 Schünemann $\mathrm{HJ}$, Wiercioch W, Brozek J, et al. Grade evidence to decision (ETD) frameworks for adoption, adaptation, and de novo development of trustworthy recommendations: GRADEADOLOPMENT. J Clin Epidemiol 2017;81:101-10

8 Andrews J, Guyatt G, Oxman AD, et al. Grade guidelines: 14. going from evidence to recommendations: the significance and presentation of recommendations. J Clin Epidemiol 2013;66:719-25

9 Rzewuska M, Duncan EM, Francis JJ, et al. Barriers and facilitators to implementation of antibiotic stewardship programmes in hospitals in developed countries: insights from transnational studies. Front Sociol 2020;5:41.

10 Scott IA, Guyatt GH. Clinical practice guidelines: the need for greater transparency in formulating recommendations. Med J Aust 2011;195:29-33. 
11 O'Neill J. Tackling drug-resistant infections globally: final report and recommendations. London, 2016.

12 CDC. Antibiotic resistance threats in the United States, 2019. Atlanta, GA, 2019.

13 Chow AW, Benninger MS, Brook I, et al. IDSA clinical practice guideline for acute bacterial rhinosinusitis in children and adults. Clin Infect Dis 2012;54:e72-112.

14 Guidelines loMUCoSfDTCP. Clinical practice guidelines we can trust. Washington (DC): national academies press (US), 2011. https://www.ncbi.nlm.nih.gov/books/NBK209539/?report=classic

15 Knowles R, Sharland M, Hsia Y, et al. Measuring antibiotic availability and use in 20 low- and middle-income countries. Bull World Health Organ 2020;98:177-87.

16 Sharland M, Gandra S, Huttner B, et al. Encouraging AWaReness and discouraging inappropriate antibiotic use-the new 2019 essential medicines list becomes a global antibiotic stewardship tool. Lancet Infect Dis 2019;19:1278-80.

17 Schünemann HJ, Hill SR, Kakad M, et al. Transparent development of the who rapid advice guidelines. PLoS Med 2007;4:e119-e.

18 Brouwers MC, Kerkvliet K, Spithoff K, et al. The agree reporting checklist: a tool to improve reporting of clinical practice guidelines. BMJ 2016;352:i1152.

19 Brouwers MC, Spithoff K, Lavis J, et al. What to do with all the agrees? the agree portfolio of tools to support the Guideline enterprise. J Clin Epidemiol 2020;125:191-7.

20 Moberg J, Oxman AD, Rosenbaum S, et al. The grade evidence to decision (ETD) framework for health system and public health decisions. Health Res Policy Syst 2018;16:45.

21 Alonso-Coello P, Schünemann HJ, Moberg J, et al. Grade evidence to decision (ETD) frameworks: a systematic and transparent approach to making well informed healthcare choices. 1: introduction. BMJ 2016:i2016.

22 Ontario $\mathrm{PH}$. Ontario gonorrhea testing and treatment guide. 2 edn, 2018.

23 Organization WH. The use of antiretroviral drugs for treating and preventing HIV infection, 2016.

24 Kawaguchi R, Matsumoto K, Akira S, et al. Guidelines for office gynecology in Japan: Japan Society of obstetrics and gynecology (JSOG) and Japan association of obstetricians and Gynecologists (JAOG) 2017 edition. J Obstet Gynaecol Res 2019;45:766-86.

25 World Health Organization. Anonymous. recommendations for investigating contacts of persons with infectious tuberculosis in lowand middle-income countries, 2012.

26 Di Comite AE S, Villani A, Stronati M, et al. Italian pediatric, T. B. Study Group. How to manage neonatal tuberculosis. J Perinatol 2016;36:80-5

27 CfDCa P, Centers for Disease Control and Prevention. Provisional CDC guidelines for the use and safety monitoring of bedaquiline fumarate (Sirturo) for the treatment of multidrug-resistant tuberculosis. MMWR Recomm Rep 2013;62:1-12.

28 Wald ER, Applegate KE, Bordley C, et al. Clinical practice guideline for the diagnosis and management of acute bacterial sinusitis in children aged 1 to 18 years. Pediatrics 2013;132:e262-80

29 Workowski KAB GA. Sexually transmitted diseases treatment guidelines, 2015. article. Atlanta, Georgia, 2015.

30 Desrosiers M, Evans GA, Keith PK, et al. Canadian clinical practice guidelines for acute and chronic rhinosinusitis. Allergy Asthma Clin Immunol 2011;7:2.

31 Mayor MT, Roett MA, Uduhiri KA. Diagnosis and management of gonococcal infections. Am Fam Physician 2012;86:931-8

32 Kaplan JEB C, Holmes KH, Brooks JT, Pau A, Masur H. Guidelines for prevention and treatment of opportunistic infections in HIV-infected adults and adolescents: recommendations from CDC, the National Institutes of Health, and the HIV Medicine Association of the Infectious Diseases Society of America. MMWR. 2009; Recommendations and reports:Morbidity and mortality weekly report. Recommendations and reports / Centers for Disease Control. 58 (RR-4) (pp 1-207; quiz CE1-2074).

33 Bradley JS, Byington CL, Shah SS. The management of community-acquired pneumonia in infants and children older than 3 months of age. Clin Infect Dis. 2011.

34 Harmes KM, Blackwood A, Burrows HI, et al. Diagnosis and management of acute otitis media. American Academy of Family Physicians 2013.

35 Adult sinusitis. Otolaryngol Head Neck Surg 2015.

36 Otitis media with effusion (OME). Otolaryngol Head Neck Surg 2016.

37 Nahid P, Dorman SE, Alipanah N. Official American thoracic Society/Centers for disease control and Prevention/Infectious diseases Society of America clinical practice guidelines: treatment of drug-susceptible Tuberculosisof drug-susceptible tuberculosis: official ATS/CDC/IDSA clinical practice guidelines. Clin Infect Dis 2016.

38 Respiratory illness in children and adults, diagnosis and treatment of, 2017. Available: Institute for Clinical Systems Improvement

39 IDSA - Infectious Diseases Society of America. Clinical Practice Guideline for the Diagnosis and Management of Group A Streptococcal Pharyngitis: 2012 Update by the Infectious Diseases Society of America [Guideline], 2012. Available: http://cid. oxfordjournals.org/content/early/2012/09/06/cid.cis629.full

40 Borisov AS, Bamrah Morris S, Njie GJ, et al. Update of recommendations for use of once-weekly Isoniazid-Rifapentine regimen to treat latent Mycobacterium tuberculosis infection. MMWR Morb Mortal Wkly Rep 2018;67:723-6.

41 Pogany L, Romanowski B, Robinson J, et al. Management of gonococcal infection among adults and youth: new key recommendations. Can Fam Physician 2015;61:869-73.

42 Rosenfeld RM, Piccirillo JF, Chandrasekhar SS, et al. Clinical practice guideline (update): adult sinusitis. Otolaryngol Head Neck Surg 2015;152:S1-39.

43 Report MaMW. Guidelines for the prevention and treatment of opportunistic infections among HIV-exposed and HIV-infected children, 2009.

44 Canada PHAo. Canadian tuberculosis standards. 7 edn, 2014.

45 Control BCfD. Sexually transmitted infections in adolescents and adults, 2014.

46 CfDCa P. Guidelines for the prevention and treatment of opportunistic infections in adults and adolescents with HIV. Prevention CfDCa 2019.

47 America IDSo. Clinical practice guidelines by the infectious diseases Society of America for the treatment of methicillin- resistant Staphylococcus aureus infections in adults and children, 2011.

48 Infections CGoST. Gonococcal infections chapter, 2013.

49 Prevention CfDCa. Guidelines for the prevention and treatment of opportunistic infections in HIV-exposed and HIV-infected children, 2013.

50 University of Michigan Health System. Pharyngitis, 2013.

51 HIV/AIDS BCCfEi. Therapeutic guidelines for antiretroviral (ARV) treatment in adult HIV infection, 2015

52 Mandell LA, Wunderink RG, Anzueto A, et al. Infectious diseases Society of America/American thoracic Society consensus guidelines on the management of community-acquired pneumonia in adults. Clin Infect Dis 2007;44 Suppl 2:S27-72.

53 US Preventive Services Task Force. Ocular prophylaxis for gonococcal ophthalmia neonatorum: preventive medication, 2019.

54 Jereb JA, Goldberg SV, Powell K. Recommendations for use of an isoniazid-rifapentine regimen with direct observation to treat latent Mycobacterium tuberculosis infection; 2011: 1650-3. http://www. ncbi.nlm.nih.gov/pubmed/22157884

55 National Collaborating Centre for Women's and Children's Health NGC:007182 [Guideline Clearing Report]. AHRQ - Agency for Healthcare Research + Quality. Surgical management of otitis media with effusion in children; 2008. http://guidelines.gov/summary/ summary.aspx?doc_id=14314\&nbr=7182

56 Bignell C, Unemo M, European STI Guidelines Editorial Board. 2012 European guideline on the diagnosis and treatment of gonorrhoea in adults. Int J STD AIDS 2013;24:85-92.

57 Bignell C, Fitzgerald M, et al, Guideline Development Group. Uk national guideline for the management of gonorrhoea in adults, 2011. Int J STD AIDS 2011;22:541-7.

58 Harris M, Clark J, Coote N, et al. British thoracic Society guidelines for the management of community acquired pneumonia in children: update 2011. Thorax 2011;66 Suppl 2:ii1-23.

59 Migliori GB, Zellweger JP, Abubakar I, et al. European Union standards for tuberculosis care. Eur Respir J 2012;39:807-19.

60 Woodhead M, Blasi F, Ewig S, et al. Guidelines for the management of adult lower respiratory tract infections--full version. Clin Microbiol Infect 2011;17 Suppl 6:E1-59.

61 Spindler C, Strålin K, Eriksson L, et al. Swedish guidelines on the management of community-acquired pneumonia in immunocompetent adults--Swedish Society of Infectious Diseases 2012. Scand J Infect Dis 2012;44:885-902

62 Thwaites G, Fisher M, Hemingway C, et al. British infection Society guidelines for the diagnosis and treatment of tuberculosis of the central nervous system in adults and children. $J$ Infect 2009;59:167-87.

63 Bignell C, IUSTI/WHO. 2009 European (IUSTI/WHO) guideline on the diagnosis and treatment of gonorrhoea in adults. Int J STD AIDS 2009;20:453-7.

64 Internal clinical guidelines T. tuberculosis prevention, diagnosis, management and service organization. National Institute for health and care excellence (UK) 2016;01:01. 
65 Menéndez R, Torres A, Aspa J, et al. [Community acquired pneumonia. New guidelines of the Spanish Society of Chest Diseases and Thoracic Surgery (SEPAR)]. Arch Bronconeumol 2010;46:543-58.

66 National Institute for Health and Clinical Excellence - Clinical Guidelines.. Respiratory tract infections (self-limiting): prescribing antibiotics, 2008.

67 British Infection Association. Guidelines for the management of community-acquired pneumonia in adults, 2009

$68 \mathrm{Cpg}$ on the diagnosis, treatment and prevention of tuberculosis. GuiaSalud 2010.

69 National Institute for Health and Clinical Excellence - Clinical Guidelines. Sinusitis (acute): antimicrobial prescribing, 2017.

70 British Association for Sexual Health and HIV. British association for sexual health and HIV national guideline for the management of infection with Neisseria gonorrhoeae, 2019.

71 Stahl JP, Azouvi P, Bruneel F, et al. Guidelines on the management of infectious encephalitis in adults. Med Mal Infect 2017;47:179-94.

72 Heidemann CL J, Berg J, Christensen JJ, et al. Danish guidelines on management of otitis media in preschool children, 2016.

73 SIGN. Management of sore throat and indications for tonsillectomy, 2010.

74 Excellence ENIfHaC. Sore throat (acute): antimicrobial prescribing, 2018.

75 Excellence NIfHaC. Pneumonia (community-acquired): antimicrobial prescribing, 2019.

76 Wiersinga WJ, Bonten MJ, Boersma WG, et al. Management of community-acquired pneumonia in adults: 2016 guideline update from the Dutch Working Party on antibiotic policy (swab) and Dutch association of chest physicians (NVALT). Neth J Med 2018;76:4-13.

77 Athlin S, Lidman C, Lundqvist A, et al. Management of communityacquired pneumonia in immunocompetent adults: updated Swedish guidelines 2017. Infect Dis 2018;50:247-72.

78 Chiappini E, Mazzantini R, Bruzzese E, et al. Rational use of antibiotics for the management of children's respiratory tract infections in the ambulatory setting: an evidence-based consensus by the Italian Society of preventive and social pediatrics. Paediatr Respir Rev 2014;15:231-6.

79 Gupta D, Agarwal R, Aggarwal A, et al. Guidelines for diagnosis and management of community-and hospital-acquired pneumonia in adults: Joint ICS/NCCP(I) recommendations. Lung India 2012;29:27-62.

80 Abdul Rahaman JA, Ker HB, Yusof M, Yusof M, et al. Tuberculosis in adults. Malays Fam Physician. 2014;9:34-7.

81 Ministry of Public Health/Qatar. Community acquired pneumonia [Guideline], 2016updated 19.03.2017. Available: https://www. moph.gov.qa/health-strategies/Documents/Guidelines/MOPH\% 20Guideline\%20-\%20Community\%20acquired\%20pneumonia\% 20v2-1\%20FINAL.pdf

82 HTA DoH - HTA Unit, Ministry of Health. Management of otitis media with effusion in children, 2012. Available: http://www.moh. gov.my/attachments/7779.pdf

83 Lee MS, Oh JY, Kang Cl, et al. Guideline for antibiotic use in adults with community-acquired pneumonia. Infect Chemother 2018;50:160-98.

84 Singapore $\mathrm{MoH}$. Prevention, diagnosis and management of tuberculosis, 2016.

85 Memish ZA, Arabi YM, Ahmed QA, et al. Management and prevention strategies for community-acquired pneumonia in the Gulf Corporation Council. J Chemother 2007;19 Suppl 1:3346:33-46.
86 Corrêa RdeA, Lundgren FLC, Pereira-Silva JL, et al. Brazilian guidelines for community-acquired pneumonia in immunocompetent adults - 2009. J Bras Pneumol 2009;35:574-601.

87 Boyles TH, Brink A, Calligaro GL, et al. South African guideline for the management of community-acquired pneumonia in adults. $J$ Thorac Dis 2017;9:1469-502.

88 Chaves NJ PG, Biggs BA, Thambiran A. on behalf of the Australasian Society for Infectious Diseases and Refugee Health Network of Australia Guidelines writing group. In: Recommendations for comprehensive post-arrival health assessment for people from refugee-like backgrounds Australasian Society for infectious diseases and refugee health network of Australia. 2 edn, 2010.

89 World Health Organisation Guidelines. WHO guidelines for the treatment of Neisseria gonorrhoeae, 2016.

90 Anonymous. World Health Organization. WHO consolidated guidelines on drug-resistant tuberculosis treatment, 2019.

91 World Health Organization. Improving the diagnosis and treatment of smear-negative pulmonary and extrapulmonary tuberculosis among adults and adolescents. recommendations for HIV-prevalent and resource-constrained settings, 2007.

92 World Health Organization 2nd WHO Guidelines Approved by the Guidelines Review Committee. Guidance for national tuberculosis programmes on the management of tuberculosis in children, 2014.

93 World Health Organisation Guidelines. Guidelines on the management of latent tuberculosis infection, 2015.

94 World Health Organisation Guidelines. Recommendation on 36 months isoniazid preventive therapy to adults and adolescents living with HIV in resource-constrained and high TB and HIV-prevalence settings: 2015 update, 2015.

95 World Health Organisation HIV Guidelines. Intensified tuberculosis case-finding and isoniazid preventive therapy for people living with HIV in resource-constrained settings, 2011.

96 Organization WH. Latent tuberculosis infection updated and consolidated guidelines for programmatic management, 2018.

97 Organization WH. Recommendations for management of common childhood conditions newborn conditions, dysentery, pneumonia, oxygen use and delivery, common causes of fever, severe acute malnutrition and supportive care, 2012.

98 Prevention CfDCa. Managing drug interactions in the treatment of HIV-related tuberculosis, 2013.

99 Tonelli M, Connor Gorber S, Moore A, et al. Recommendations on routine screening pelvic examination: Canadian Task force on preventive health care adoption of the American College of physicians guideline. Can Fam Physician 2016;62:211-4.

100 Darzi A, Abou-Jaoude EA, Agarwal A, et al. A methodological survey identified eight proposed frameworks for the adaptation of health related guidelines. J Clin Epidemiol 2017;86:3-10.

101 Organization WH. Global antimicrobial resistance and use surveillance system (glass) report, 2020.

102 Organization WH. Worldwide country situation analysis: response to antimicrobial resistance 2015. Available: https://apps. who.int/ iris/bitstream/handle/10665/163468/9789241564946_eng.pdf? sequence $=1$

103 Organization WH. Who model Lists of essential medicines, 2019.

104 Foundation AtM. Antimicrobial resistance benchmark, 2018. Available: https://accesstomedicinefoundation.org/media/uploads/ downloads/5bc5edd8367eb_Antimicrobial-Resistance-Benchmark2018.pdf 